\title{
Binary Logistic Regression Analysis of Prevalence of Depression and Anxiety among University Students in India during COVID-19 Pandemic
}

\author{
Narayanan Madathil1, Judewin Lucio Noronha² ${ }^{2}$ Kashish Dungar ${ }^{3}$, Poonam Soni ${ }^{4}$ \\ 1,2,3Chemical Engineering, Thadomal Shahani Engineering College \\ ${ }^{4}$ Applied Mathematics Department, Thadomal Shahani Engineering College
}

\begin{abstract}
Covid 19 has posed grave challenges and caused serious disruptions and distress across the world. On one hand the imposition of nationwide lockdowns has helped to curb the virus on the other hand it has resulted in significant damage to public mental health. The aim of this study was to investigate the prevalence of depression and anxiety among students of various universities in India during the COVID-19 pandemic. It also aimed at identifying the factors and determinants of depression and anxiety. A total of 138 university students living in various parts of India, accepted to participate in this crosssectional web-based survey. A standardized e-questionnaire was generated using the Google Form, and the link was shared through social media, mainly via WhatsApp. The information was analysed in three consecutive levels, such as, univariate, bivariate, and multivariate analysis. Around $14.4 \%$ of the students reportedly had moderately severe depression, whereas $18.1 \%$ were severely suffering from anxiety. The binary logistic regression suggests that students in the age range 21-23 have greater depression $(\mathrm{OR}=3.009,95 \% \mathrm{CI}=1.072-8.446)$. It is also evident that students who were not provided with tuition in the pre-pandemic period had depression $(\mathrm{OR}=0.699$, $95 \% \mathrm{CI}=0.250-1.957)$.
\end{abstract}

Key Words: Covid-19, Binary Logistic Regression, Anxiety, Depression.

\section{INTRODUCTION}

SARS Cov-2, more commonly known as the Coronavirus, is a deadly, highly infectious virus that can spread from an infected person's mouth or nose in small liquid particles when they cough, sneeze, speak, sing or breathe. Globally, as of 3 September 2021, there have been $218,946,836$ confirmed cases of COVID-19, including 4,539,723 deaths reported to WHO [1].

In India, there have been 439,895 deaths, and 32,903,289 cases of Covid-19. It is well known that pandemics pose a threat to mental health. A WHO survey of 130 countries provides the first global data showing the devastating impact of COVID-19 on access to mental health services.[1] The COVID-19 pandemic has disrupted or halted critical mental health services in $93 \%$ of countries worldwide, while the demand for mental health is increasing, as the resulting economic recession has negatively affected many people's mental health and created new obstacles for people already suffering from mental illness and substance use disorders.[2,3] Young adults have experienced a number of pandemic-related consequences, such as closures of universities and loss of income, that may contribute to poor mental health. This distress may be further exacerbated in individuals who have experienced prior traumatic events. Depression and anxiety symptoms were significantly elevated relative to usual population data, including for individuals with no existing mental health diagnosis. [2,4].

Bereavement, isolation, loss of income and fear are triggering mental health conditions or aggravating existing ones with three-quarters reported at least partial disruptions to school and workplace mental health services $(78 \%$ and $75 \%$ respectively). Over $60 \%$ reported disruptions to mental health services for vulnerable people, including children and adolescents (72\%), who experienced a clinically significant change in psychopathological symptom levels from pre- to postoutbreak assessment or significant levels of COVID-19-related traumatic distress. [3,5]. For Indians, demanding situations of the medical sector, in addition deepens the concerns that heighten mental distress [6]. The uncertainty regarding the mode of examinations in their schools and colleges, and availability of jobs, etc. has been a cause of distress among the students all over the world. Initial enthusiasm and engagement witnessed during online classes has subsided and in spite of teachers trying their level best to teach students online, the impact of such teaching is not optimum. The primary reason being that all students are unable to afford online platform usage and smoothly transition to online learning which can have a huge negative effect on students' career paths [7]. The presence of anxiety issues among students during Covid-19 has been related to their poor economic conditions, daily life events and hampered academic activities [8]. High levels of anxiety were found among Indians during the Covid-19 outbreak [9].

The current study aimed to improve our understanding of the mental health consequences of COVID-19 on college students and investigate the weightage of the probable determinants and factors for the same.

\section{MATERIALS AND METHODS}

The survey targeted the students of Indian universities. It was circulated in the form of a Google form via WhatsApp groups and was collected in the months of April and May, 2021. PHQ-9 and GAD-7 questionnaires to collect information regarding depression and anxiety respectively. The data so obtained was analyzed using SPSS and correlational and bilinear logistic regression analysis was carried out.

Convenience sampling method was used for this survey. Before the form revealed the questions, an e-consent was taken from the participants to participate in the survey. 


\section{International Journal of Scientific Research in Engineering and Management (IJSREM)}

Brief Profile of the respondents: This section contained some basic information about the students who participated in the study. The questions were centred around - gender (male/female); age group (17-20, >20); University (Mumbai University/other); knowledge about the current rise in covid cases (yes/no); staying with family (yes/no); anyone in family affected by the coronavirus (yes/no); studies affected by the pandemic (yes/no); transition from offline to online beneficial (yes/no); desk-bound lifestyle (yes/no); able to dedicate more time to activities you enjoy during pandemic (yes/no); saved commuting hours during pandemic (yes/no); tuitions before lockdown (yes/no); and monthly income more or less than certain ranges(yes/no).

Depression: Patient Health Questionnaire (PHQ-9) was used to decide the depression level in the participants. PHQ is a very efficient way of finding depression. It consists of 9 questions, each of which are graded from $0-3$, with 0 indicating not at all, to 3 indicating nearly every day. The final scores for each participant ranged between 0-27, wherein a person having a score between 0-4 would have no depression, 5-9 would have mild, 10-14 would have moderate, 15-19 would have moderately severe, and 20-27 would have severe depression.

Anxiety: Generalised Anxiety Disorder (GAD-7) was used to decide the anxiety level in the participants. GAD is a very efficient way of finding anxiety. The questionnaire has 7 questions, which are graded from $0-3$, with 0 indicating not at all, to 3 indicating nearly every day. The final scores for each participant ranged between $0-21$, wherein a person having a score between 0-5 would have no anxiety, 5-9 would have mild anxiety, 10-14 would have moderate anxiety, and 15-21 would have severe anxiety.

A frequency table, depicting the basic information of the respondents obtained in the survey, was prepared. Binary logistic regression [10] was used to identify variables influencing depression and anxiety among students by categorizing the outcome variable was categorized into two categories, i.e., depressed = 'yes' and 'no' and anxious = 'yes' and 'no, the various probable determinants influencing depression and anxiety were analysed using Binary logistic regression and this provided an insight into the degree to which different factors are influencing the outcomes. Logistic regression generates the coefficients (and its standard errors and significance levels) of a formula to predict a logit transformation of the probability of the presence of the characteristic of interest:

$$
\operatorname{logit}(\pi)=\alpha+\beta_{1} \mathrm{X}_{1}+\beta_{2} \mathrm{X}_{2}+\beta_{3} \mathrm{X}_{3}+\beta_{4 \mathrm{X}_{4}}+\ldots+\beta_{\mathrm{k}} \mathrm{Xk}_{\mathrm{k}}
$$

where, $\pi$ is the probability of the outcome of interest given that $\mathrm{X}=\mathrm{x}, \alpha$ is a parameter which represents the $\mathrm{Y}$-intercept, and $\beta$ s are parameters of the slope, $X$ can be qualitative (categorical) or quantitative variable, and $\mathrm{Y}$ is always qualitative or categorical. The logit transformation was defined as the logged odds:

$$
\text { Odds }=\frac{\pi}{1-\pi}
$$

\section{RESULTS}

It was found that 45 students (32.6\%) student respondents were affected by Covid-19. The statistics shown that 116 students $(84.05 \%)$ felt that their studies were impacted deeply due to the pandemic. 97 students $(70.28 \%)$ found that online studies hampered and affected their learning. 109 students (78.98\%) responded that they were able to save commuting hours by studying at home.

\begin{tabular}{|c|c|c|c|c|c|c|c|c|c|}
\hline \multirow[b]{2}{*}{ Variables } & \multicolumn{5}{|c|}{ Depression } & \multicolumn{4}{|c|}{ Anxiety } \\
\hline & None & Mild & Moderate & Moderately Severe & Severe & None & Mild & Moderate & Severe \\
\hline \multicolumn{10}{|c|}{ Has anyone in your family becen uffected by dic corvusvinus? } \\
\hline Yes & 6 & 17 & 10 & 5 & 4 & 13 & 14 & 7 & 11 \\
\hline No & 15 & 31 & 19 & 12 & 1.3 & 29 & 34 & 16 & 11 \\
\hline \multicolumn{10}{|c|}{ 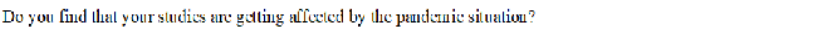 } \\
\hline Yes & 15 & 41 & 28 & 17 & 15 & 30 & 43 & 20 & 23 \\
\hline No & 6 & 10 & 1 & 3 & 2 & 12 & 5 & 3 & 2 \\
\hline \multicolumn{10}{|c|}{ Have you found the transition from offline to on line classes to be beneticial? } \\
\hline Yes & 11 & 16 & 3 & 6 & 5 & 17 & 11 & 9 & 4 \\
\hline No & 10 & 35 & 26 & 14 & 12 & 25 & 37 & 14 & 21 \\
\hline \multicolumn{10}{|c|}{ Tlave you saved commuting hours during this pandemic? } \\
\hline Yes & 18 & 40 & 23 & 15 & 13 & 34 & $3 ?$ & 12 & 19 \\
\hline No & 3 & 11 & 6 & 5 & 4 & 8 & 11 & 4 & 6 \\
\hline \multicolumn{10}{|c|}{ What is the total monthly income of your family? } \\
\hline <Rs 50000 & 0 & 8 & 7 & 7 & 1 & 1 & 9 & 7 & 6 \\
\hline Ks $50000-$ Ks 100000 & 9 & 15 & 8 & 4 & 9) & 12 & 14 & 7 & 12 \\
\hline Rs $100000-12 s 500000$ & $?$ & 16 & 7 & 7 & 1 & 17 & 13 & 4 & 4 \\
\hline$>R_{5} 500000$ & 5 & 12 & 7 & 2 & 3 & 9 & 12 & 5 & 3 \\
\hline \multicolumn{10}{|c|}{ Befure lockdowi, did you go for classes/uilions? } \\
\hline$Y=s$ & 9 & 21 & 16 & 6 & 4 & 19 & 19 & 11 & 7 \\
\hline No & 12 & 30 & 13 & 14 & 13 & 23 & 29 & 12 & 18 \\
\hline \multicolumn{10}{|c|}{ Are you living a desk-bound lifestyle? } \\
\hline Yes & 9 & 39 & 21 & 15 & 14 & 30 & 32 & 14 & 22 \\
\hline No & 12 & 12 & 8 & 5 & 3 & 12 & 16 & () & 3 \\
\hline \multicolumn{10}{|l|}{ Gender } \\
\hline Male & 23 & 27 & 18 & 11 & 5 & 26 & 34 & 15 & 9 \\
\hline Funale & 9 & 19 & 15 & 9 & 2 & 16 & 14 & 8 & 16 \\
\hline Other & 0 & 0 & 0 & 0 & 0 & 0 & 0 & 0 & 0 \\
\hline \multicolumn{10}{|l|}{ Age group } \\
\hline $17-20$ & 13 & 17 & 13 & 7 & 4 & 18 & 13 & 13 & 10 \\
\hline $21-23$ & 19 & 27 & 20 & 13 & 3 & 23 & 34 & 10 & 15 \\
\hline$>23$ & 0 & 2 & 0 & 0 & 0 & 1 & 1 & 0 & 0 \\
\hline \multicolumn{10}{|c|}{ Are you staying will your: } \\
\hline Fuwily & 29 & 45 & 31 & 18 & 7 & 39 & 46 & 21 & 24 \\
\hline l'riends & 2 & 1 & 2 & 0 & 0 & 2 & 2 & 0 & 1 \\
\hline Relatives & 0 & 0 & 0 & 2 & 0 & 0 & 0 & 2 & 0 \\
\hline Roumwaliss & 1 & 0 & 0 & 0 & 0 & 1 & 0 & 0 & 0 \\
\hline
\end{tabular}

\section{Table-1}

The survey consisted of $39.14 \%$ of females and 84 males. 59.42\% were aged between $21-23,39.13 \%$ were aged from $17-20$ and the rest were greater than 23 . Around $5.08 \%$ of the students were not a part of Mumbai University while the rest $44.92 \%$ were a part of Mumbai University. $94 \%$ of the students had family to stay with, while the rest were divided into their staying with their friends $(3.62 \%)$, relatives $(1.44 \%)$ and roommates $(0.74 \%), 32.76 \%$ of the students had family members who were affected by Covid-19, $84.05 \%$ students felt that their studies were affected due to the pandemic. $70.28 \%$ of the students felt that the transition from offline to online, hampered their ability to learn and therefore did not find it beneficial. Students were asked about their monthly income and they were segregated as follows: $32.62 \%$ of students have a monthly income from their family of Rs 50000 - Rs 100000 . 
$27.53 \%$ of student families receive a monthly income of between Rs 100000 - Rs 500000. 21.1\% students have a family income of more than Rs 500000. While the remaining students, i.e., $18.84 \%$ have an income of less than Rs $50000.40 .58 \%$ of students would go for classes and tuition. A shocking number of students, $71.02 \%$ live an extremely desk bound lifestyle.

Table-2 Analysis of Depression dataset from SPSS

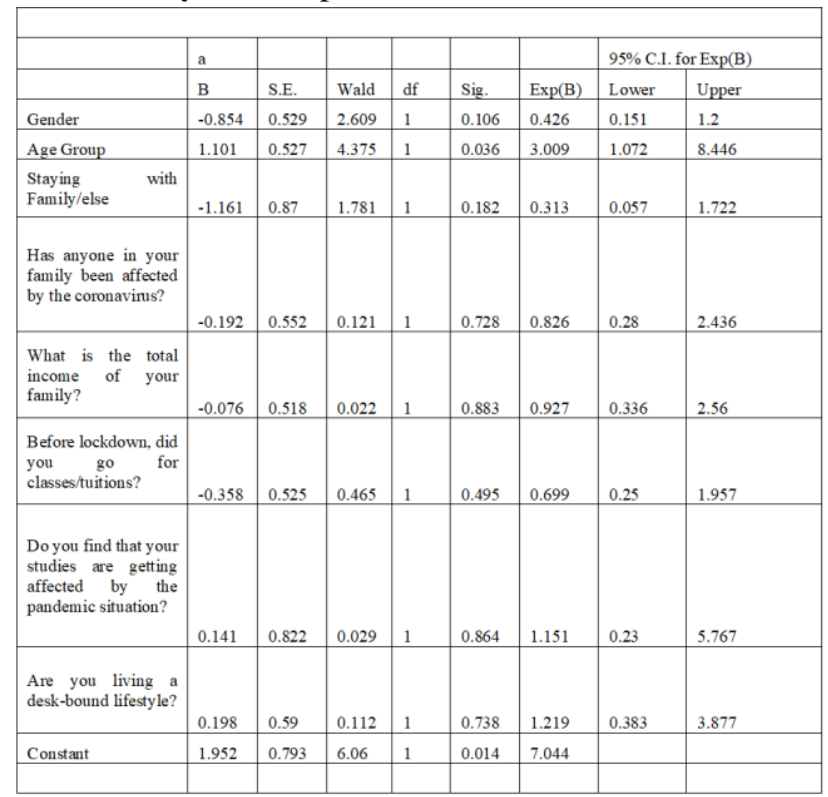

Table-3 Analysis of Anxiety dataset from SPSS

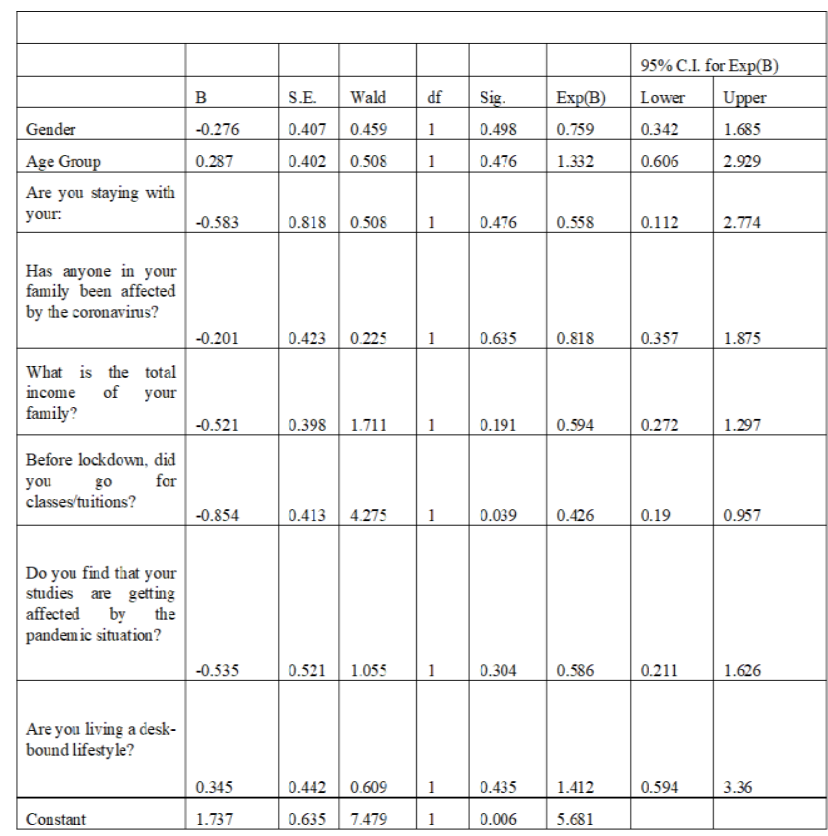

Students of age above 20 were 3 times more depressed and 1.3 times more anxious than students under the age 20. Students who feel that their studies are being affected during this pandemic are 1.15 times more depressed than students who feel the opposite.

Students living a desk-bound lifestyle are 1.22 times more depressed and 1.41 times more anxious than the ones who are engaged in some kind of activity. 117 students (84.78\%) were diagnosed with Depression on the basis of the PHQ scale. From the survey, after carrying out analysis and grading it on the GAD scale, 96 students $(69.56 \%)$ were found to have anxiety.

\section{CONCLUSION:}

The current study is an effort in the direction of investigating the presence and levels of anxiety and depression among university students in India. The findings of the research suggest that pandemic has caused adverse psychological effects on students affecting their mental health. The small size of sample has been a limitation of the research still the results or findings of the study are significant and can be used by authorities or agencies committed to work for the better mental health of students.

\section{REFERENCES:}

[1] https://covid19.who.int/

[2]https://www.kff.org/coronavirus-covid-19/issue-brief/theimplications-of-covid-19-for-mental-health-and-substanceuse/

[3]https://www.frontiersin.org/articles/10.3389/fpsyt.2020.579 985/full

[4]https://www.karger.com/Article/FullText/510752

[5] https://www.jmir.org/2020/9/e21279

[6] Chetterje P. Gaps in India's preparedness for COVID-19 control. The Lancet Infectious Diseases. 2020;20(5):544. doi: 10.1016/s1473-3099(20)30300-5.

[7] Agha, E. (2020, April 14). Learning rebooted: Online education during Covid-19 lockdown puts spotlight on India's digital divide. Retrieved from https://www.news18.com/news/india/learning-rebootedonline-education-during-covid-19-lockdown-putsspotlight-on-indias-digital-divide-2563265.html.

[8] Cao W, Fang Z, Hou G, Han M, Xu X, Dong J, Zheng J. The psychological impact of the COVID-19 epidemic on college students in China. Psychiatry Research. 2020 doi: 1016/j.psychres.2020.112934.

[9] Roy D, Tripathy S, Kar S, Sharma N, Verma S, Kaushal V. Study of knowledge, attitude, anxiety \& perceived mental healthcare needs in the Indian population during COVID-19 pandemic. Asian Journal of Psychiatry. 2020; 51:102083. doi: 10.1016/j.ajp.2020.102083.

[10] Hosmer DW, Lemeshow S. Applied logistic regression. 2nd ed New York: Wiley; 2000. 